\title{
On Solar Energy Utilization for Drying Technology
}

\author{
Ji Ye Yoo, Hee Jung Kim, Eun Ji Woo, and Chan Jin Park
}

\begin{abstract}
Solar drying is one of the oldest drying techniques in which solar radiation is used. Drying is an essential process in the preservation of agricultural crops and in industries, such as textile production, dairy processing, cement production, clay brick production, tile production, wood and timber processing, wastewater treatment and biomass treatment. Solar drying is another very important application of solar energy. Solar dryers use air collectors to collect solar energy. Solar dryers are used primarily by the agricultural industry. The purpose of drying an agricultural product is to reduce its moisture content to a level that prevents its deterioration. In drying, two processes take place; One is a heat transfer to the product using energy from the heating source, and the other is a mass transfer of moisture from the interior of the product to its surface and from the surface to the surrounding air. In short, we conduct a comprehensive review of summarize the research and development work for solar drying. It is hoped that this review work maybe valuable and appropriate for further development work.
\end{abstract}

Index Terms-Solar drying, solar energy, solar thermolysis.

\section{INTRODUCTION}

Solar drying is one of the oldest drying techniques in which solar radiation is used, i.e. drying under direct sunlight to preserve food or non-food products since ancient times. Solar drying does not require man produced energy, uses renewable energy and applicable in any part of the world. Nevertheless, in order to increase the efficiency of material drying using solar radiation, proper innovation or application is needed. Owing to costly, limited, and non-environmentally friendly fossil fuels, solar drying is becoming a popular option to replace the mechanical thermal dryers [1].

The main aim of this paper is to summarize the research and development work for solar drying. It is hoped that this review work maybe valuable and appropriate for greenhouse

Manuscript received August 29, 2016; revised November 4, 2016. This work was supported by Korea Ministry of Environment (MOE) as

$\ulcorner$ Knowledge-based environmental service Human resource development Project $\lrcorner$.

Ji Ye Yoo is with the Department of Climate International Cooperation, Incheon National University, Republic of Korea (e-mail: yoojiye@inu.ac.kr).

Hee Jung Kim was with the Department of Energy and Env. Engineering, Incheon National University, Republic of Korea (e-mail: kimheejung@inu.ac.kr).

Eun Ji Woo is with the Department of Energy and Env. Engineering, Incheon National University, Republic of Korea (e-mail: wej5366@inu.ac.kr).

Chan Jin Park is with the Department of Energy and Env. Engineering and the Department of Climate International Cooperation, Incheon National University, Republic of Korea (e-mail: cjpark@inu.ac.kr). gas reduction technology.

\section{HISTORY OF SOLAR ENERGY}

Probably the oldest large-scale application known to us is the burning of the Roman fleet in the bay of Syracuse by Archimedes, the Greek mathematician and philosopher (287-212 B.C.). Scientists discussed this event for centuries. From 100 B.C. TO 1100 A.D., authors made reference to this event, although later it was criticized as a myth because no technology existed at that time to manufacture mirrors [2]. The basic question was whether or not Archimedes knew enough about the science of optics to devise a simple way to concentrate sunlight to a point at which ships could be burned from a distance. Nevertheless, Archimedes had written a book, On Burning Mirrors [3], which is known only from references, since no copy survived.

During the 18th century, solar furnaces capable of melting iron, copper, and other metals were being constructed of polished iron, glass lenses, and mirrors. The furnaces were in use throughout Europe and the Middle East. One of the first chemist Lavoisier, who, around 1774, constructed powerful lenses to concentrate solar radiation [4].

During 19th century, attempts were made to convert solar energy into other forms based upon the generation of low-pressure steam to operate steam engines. August Monchot pioneered this field by constructing and operating several solar-powered steam engines between the years 1864 and 1878 in Europe and North Africa.

The efforts were continued in the United States, where John Ericsson, an American engineer, developed the first steam engine driven directly by solar energy. Ericsson built eight systems that had parabolic troughs by using either water or air as the working medium [5].

During the last 50years, many variations were designed and constructed using focusing collectors as a means of heating the transfer of working fluid that powered mechanical equipment. The two primary solar technologies used are central receivers and distributed receivers employing various point and line focus optics to concentrate sunlight. Central receiver systems use fields of heliostats(two-axis tracking mirrors) to focus the sun's radiant energy onto a single tower-mounted receiver [6]. Distributed receiver technology includes parabolic dishes, Fresnel lenses, parabolic troughs, and special bowls. Parabolic dishes track the sun in two axes and use mirrors to focus radiant energy onto a point focus receiver. Troughs and bowls are line focus tracking reflectors that concentrate sunlight onto receiver tubes along their focal lines.

Today, many large solar plants have output in the megawatt range to produce electricity or process heat. Thus, they can provide electricity or steam to drive small-capacity 
conventional desalination plants driven by thermal or electrical energy.

The manufacture of solar water heater began in the early 1960s. The industry of solar water heater manufacturing expanded very quickly in many countries of the world.

\section{DRYING PRINCIPLES}

Drying is basically a phenomena of removal of liquid by evaporation from a solid. Mechanical methods for separating a liquid from a solid are not generally considered drying. In the following section an attempt is made to provide a concise overview of the fundamental principles of drying process for agricultural products. These principles are applied, in general, to mechanical conventional drying and here concerned mainly with solar drying. However in general, must be noted that conventional drying principles and phenomena are independent of the type of energy used. A major part of energy consumption during drying is for the evaporation of liquid water in to its vapour $(2258 \mathrm{~kJ} / \mathrm{kg}$ at $101.3 \mathrm{kPa})$. The water may be contained in the solid in various forms like free moisture or bound form which directly affects the drying rate [7], [8].

Moisture content is expressed either on dry or wet basis, e.g. moisture content in wet $(X w)$ basis is the weight of moisture per unit of wet material.

$$
X_{w}=\frac{m_{w}}{m_{w}+m_{d}} k g \text { per } k g \text { of mixture }
$$

and on dry basis $(X d)$, is expressed as the ratio of water content to the weight of dry material:

$$
X_{d}=\frac{m_{w}}{m_{d}}
$$

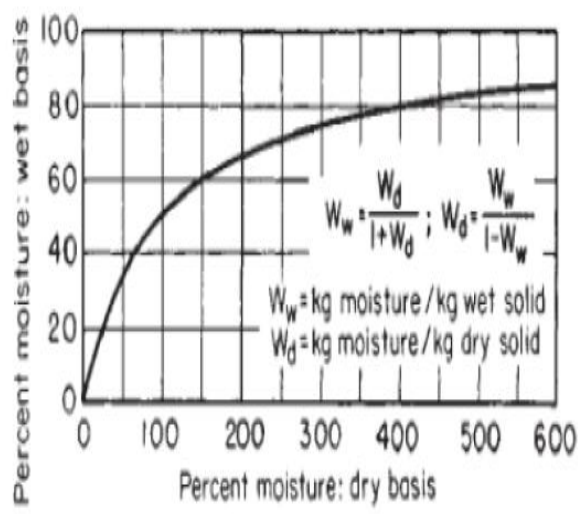

Fig. 1. Relationship between wet-weight and dry-weight basis [9].

Although the most convenient way to express moisture for mathematical calculations is on dry basis but for agricultural products moisture content normally is expressed in wet basis. Fig. 1 shows the plot of relationship between the dry and wet weight basis.

\section{SOlAR DRYING TECHNOLOGY}

Solar drying has been used since time immemorial to dry plants, seeds, fruits, meat, fish, wood, and other agricultural, forest products. In order to benefit from the free and renewable energy source provided by the sun several attempts have been made in recent years to develop solar drying mainly for preserving agricultural and forest products [1].

However, for large-scale production the limitations of open-air drying are well known.

Among these are high labour costs, large area requirement, lack of ability to control the drying process, possible degradation due to biochemical or microbiological reactions, insect infestation, and so on. The drying time required for a given commodity can be quite long and result in post-harvest losses(more than $30 \%$ ). Solar drying of agricultural products in enclosed structures by forced convection is an attractive way of reducing post-harvest losses and low quality of dried products associated with traditional open sun-drying methods [10]. In many rural locations in most developing countries, grid-connected electricity and supplies of other non-renewable sources of energy are either unavailable, unreliable or, too expensive. In such conditions, solar dryers appear increasingly to be attractive as commercial propositions [11], [12].

During the last decades, several developing countries have started to change their energy policies toward further reduction of petroleum import and to alter their energy use toward the utilization of renewable energies. With very few exceptions, the developing countries are situated in climatic zones of the world where the insolation is considerably higher than the world average of $3.82 \mathrm{kWh} / \mathrm{m} 2$ day.

An alternative to traditional drying techniques and a contribution toward the solution of the open air drying problems is the use of solar dryers. Accordingly, the availability of solar energy and the operational marketing and economy reasons offer a good opportunity for using solar drying all over the world [1].

\section{INFLUENCE FACTORS ON DRYING}

\section{A. Solar Radiation}

Solar radiation is the radiant energy received from the sun. It is the intensity of sunrays falling per unit time per unit area and is usually expressed in Watts per square meter $(\mathrm{W} / \mathrm{m} 2)$. The radiation incident on a surface varies from moment to moment depending on its geographic location (latitude and longitude of the place), orientation, season, time of day and atmospheric conditions. Solar radiation is the most important weather variable that determines whether a place experiences high temperatures or is predominantly cold. The instruments used for measuring of solar radiation are the pyranometer and the pyrheliometer. The duration of sunshine is measured using a sunshine recorder [13].

\section{B. Ambient Temperature}

The temperature of air in a shaded (but well ventilated) enclosure is known as the ambient temperature; it is generally expressed in degree Celsius $\left({ }^{\circ} \mathrm{C}\right)$. Temperature at a given site depends on wind as well as local factors such as shading, presence of water body, sunny condition, etc. When the wind 
speed is low, local factors strongly influence on temperature of air close to the ground. With higher wind speeds, the temperature of the incoming air is less affected by local factors. A simple thermometer kept in a Stevenson's screen can measure ambient temperature [13].

\section{Air Humidity}

Air humidity, which represents the amount of moisture present in the air, is usually expressed in terms of 'relative humidity'. Relative humidity is defined as the ratio of the mass of water vapour in a certain volume of moist air at a given temperature, to the mass of water vapour in the same volume of saturated air at the same temperature; it is normally expressed as a percentage. It varies considerably, tending to be the highest close to dawn when the air temperature is at its lowest, and decreasing as the air temperature rises. The decrease in the relative humidity towards midday tends to be the largest in summer. In areas with high humidity levels, the transmission of solar radiation is reduced because of atmospheric absorption and scattering. High humidity reduces evaporation of water and sweat. Consequently, high humidity accompanied by high ambient temperature causes a lot of discomfort [13].

\section{SOLAR DRYING OF FOOD}

\section{A. Tomatoes}

Due to the increasing demand to dried tomatoes from the industry, especially from the soup manufacturers, interest in producing high quality dried tomatoes has been increasing.

Therefore, it is important to establish a drying method, which yields products with higher sensory and sanitary quality in a shorter drying time compared to the conventional sun-drying method. Both 2\% Na2S205 and 2\% citric acid pretreatments can be used to protect the bright, red colour of tomatoes. However, citric acid did not prevent the growth of moulds and yeasts effectively. Therefore, dipping into sodium metabisulfite solution for 3 minute is the best type of pretreatment. Tomatoes can be dried at $55^{\circ} \mathrm{C}$ in solar tunnel dryer without a darkening in colour. At this temperature the drying takes 4-5 days to a final moisture content of $11 \%$ [14].

\section{B. Red Pepper}

Red peppers are deseeded, cut into small pieces, and washed before loading into the tunnel solar dryer. Pretreatment with 2\% Na2S205 for 1 second gives the best colour. Moreover, the drying temperature and piece size of red peppers affects the final product quality.

Temperatures higher than $60^{\circ} \mathrm{C}$ results in dark brown colour formation in red peppers. Red peppers that are cut into bigger pieces needs a longer time period to dry and therefore the colour of the final product is darker. Drying at low temperatures $\left(45-50^{\circ} \mathrm{C}\right)$ for about 1 day gives good results. To increase the capacity of the solar dryer, a double layer system can be constructed, but with this system, drying needs a more careful control. Final moisture content of dried red peppers which are pretreated with $2 \mathrm{Na} 2 \mathrm{~S} 205$ for 1 second is $3.5 \%$. The yield is $9 \%$ for both pretreated and naturally dried peppers [14].

\section{Green Pepper}

Green peppers are used especially in the soup manufacturing. Therefore, establishing an efficient and economic method for peppers is important for the food industry. Green peppers are washed, deseeded and cut into small pieces before loading into the dryer. Green peppers are very sensitive to high temperatures and light. Therefore, green peppers should be dried under dark and at $45-50^{\circ} \mathrm{C}$ to preserve the natural green colour. 2\% Na2S205 dipping for 1 sec can be applied to obtain a microbiologically safe product. Drying at $45-50^{\circ} \mathrm{C}$ under dark conditions takes about 1 day. Green peppers dried under these conditions have a final moisture content of $6 \%$, and a yield of $10 \%$ [14].

\section{Onion}

A large part of the dehydrated onion production is used as seasoning in production of catsup, chilli sauce and meat casseroles, as well as cold cuts, sausages, potato chips, crackers and other snack items. Food service outlets also use dehydrated onions because of its convenience in storage, preparation and use. Before drying, onions are peeled and sliced into desired shapes. Onions can be dried at $45-50^{\circ} \mathrm{C}$ for 2-3 days to a final moisture content of $15 \%$ in tunnel solar dryers. Sodium metabisulfite dipping can be used to preserve colour. Drying temperatures of onions should not exceed $50^{\circ} \mathrm{C}$ in order to prevent browning of the product. The yield in onion drying is $8 \%$ [14].

\section{E. Carrot}

Before loading into the dryer, carrots are peeled, washed, cut into small cubes and treated with $2 \%$ sodium metabisulfite solution for $1 \mathrm{~s}$ and $10 \mathrm{~s}$ or dried as natural. Carrots can be dried at $50-55^{\circ} \mathrm{C}$ for $1-1.5$ days to a final moisture content of $7.5 \%$. Naturally dried carrots loss their bright orange colour. The sodium metabisulfite treated ones preserve their colour to the largest extent [14].

\section{F. Apples}

Golden apples are cleaned, cored and sliced to 3-5 mm thick. To prevent browning, the apples can be immersed for $1 \mathrm{~s}$ in $2 \%$ citric acid or $2 \% \mathrm{Na} 2 \mathrm{~S} 2 \mathrm{O} 5$ solutions immediately after slicing. The apples dried under light conditions becomes a little brown but the ones that are dried without exposure to light are kept their natural, light colour. The choice of drying conditions depends on the consumer's demand. Dried apples have a water activity of 0.38 and a yield of $15 \%$ [14].

\section{G. Peaches}

Peaches are washed, destoned and sliced $1-2 \mathrm{~cm}$ thick. The thickness of the slices is very important since very thin slices causes hardening and brownish colour in the final product.

Different concentrations of $\mathrm{Na}_{2} \mathrm{~S}_{2} \mathrm{O}_{5}$ and citric acid can be used as pretreatment agent: $2 \%$ citric acid for $30 \mathrm{~s}, 1 \mathrm{Na}_{2} \mathrm{~S}_{2} \mathrm{O}_{5}$ for $1 \mathrm{~s}$, and $1 \%$ citric acid $+0.5 \% \mathrm{Na}_{2} \mathrm{~S}_{2} \mathrm{O}_{5}$ for $1 \mathrm{~s}$. Peaches which are consumed directly or used in recipes can be dried at $45-50^{\circ} \mathrm{C}$ in 2 days. The yield of the final product is $11 \%$ and final moisture content is about $8.5 \%$ [14]. 


\section{ENVIRONMENTAL SOLAR DRYING}

\section{A. Solid Waste Drying}

Solid waste drying beds are provided to allow surplus solid waste that is withdrawn from the process to dry for easier handling. Solid waste drying relies on an underground drainage system as well as sunshine.

The exchange of mass and heat between dried solid waste and air (material and factor) is of essential significance for the drying process. The heat exchange is achieved through radiation, convection and conduction. Moisture mass goes from the area of higher concentration to the area of smaller concentration as a result of diffusion. While being in contact with the heated factor moisture from the surface of solid waste evaporates to the air. The rate of moisture evaporation differs for materials depending on their properties. It is highest in the first phase of drying when water content in solid waste is greatest. Then it diminishes. The rate of moisture evaporation depends also on the contact surface of a drying medium and a dried material. The more extended the contact surface is the higher rate of moisture evaporation can be obtained.

In case of solid waste the extension of the contact surface can be achieved through granulation. Granulation extends the contact surface of the drying medium and the dried material which keeps the drying rate at a high level what is the basic condition for making the drying process economically rational [15].

Fig. 2 shows the process in which solar drying in the solid waste.

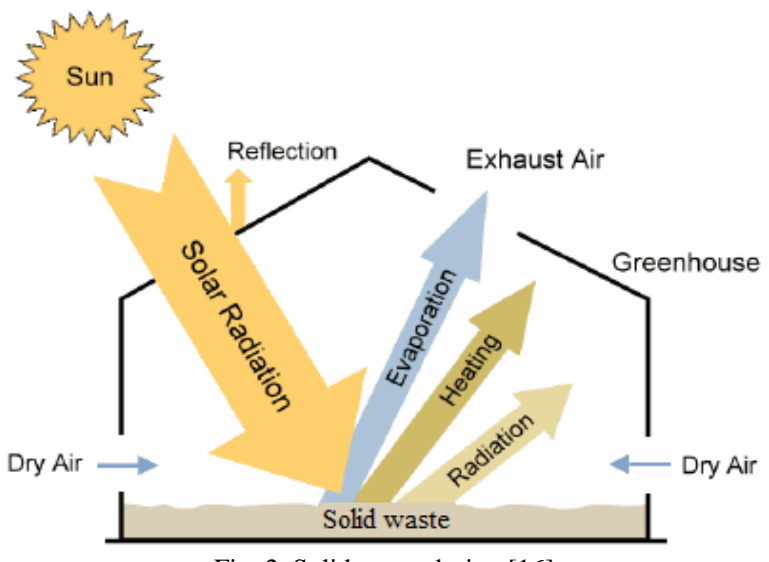

Fig. 2. Solid waste drying [16].

\section{B. Solar Thermochemical Processes}

On abroad basis, solar thermochemical processes can be classified as processes for production of fuels(hydrogen/ syngas) and industrial commodities. Solar fuels like hydrogen can be produced by solar thermolysis or in a thermochemical cycle while syngas can be obtained by upgrading of carbonaceous feed or from carbon dioxide and water splitting in a thermochemical cycle. Solar thermolysis involves direct dissociation of water at elevated temperature of $1900-4000 \mathrm{~K}$ by using process heat [17].

Solar energy can also be used for reforming and gasification of carbonaceous feed like coal, methane and biomass that results in net embodied solar energy in the product gases.
Thermochemical cycles are a series of chemical reactions that split water and carbon dioxide to produce hydrogen and carbon/carbon monoxide respectively. Syngas can also be obtained in a thermochemical cycle with net input of water-carbon dioxide mixture. As compared to solar thermolysis, the reactions in thermochemical cycles occur at lower temperature(800-2100K). Thermochemical cycles are classified as multi-step thermochemical cycles and metal oxide redox pair based cycles. Multi-step thermochemical cycles are based on compounds of elements like sulphur, chlorine, bromine etc. These chemicals undergo a series of reactions to split water for producing hydrogen and oxygen in different stages of the reaction. Multi-step cycles are further classified as pure thermal or hybrid cycles depending on the absence or requirement of an electrolysis step. In metal oxide cycles, the redox material undergoes cyclic reduction and oxidation reactions for producing oxygen and hydrogen respectively. Metal oxide cycles are further classified as volatile or non-volatile cycles depending on the redox material used.

Solar thermochemical processes can also be used for producing many industrial commodities and has huge potential in industries like metal and cement. Metals like iron, zinc and aluminium can be produced by solar driven dissociation and reduction reactions. Lime can be obtained by solar dissociation of limestone. Industrial waste like automobile shredder residue(ASR), electric arc furnace dust (EAFD) can be recycled while organic waste and landfill gas can be upgraded by solar thermochemical processes. Fullerenes and carbon nanotubes can be obtained by catalytic thermal decomposition of methane or by evaporation of carbon.

\section{Solar Thermolysis}

A conceptually easy way for solar hydrogen production is to dissociate water by heating it to a sufficient temperature so that $\Delta \mathrm{G}_{\text {reaction }} \leq 0$.

$$
\mathrm{H}_{2} \mathrm{O} \rightarrow \mathrm{H}_{2}+\frac{1}{2} \mathrm{O}_{2}
$$

The temperature required for solar thermolysis is very high. It is estimated that at atmospheric pressure, $\Delta \mathrm{G}$ for the dissociation reaction reaches zero at $4300 \mathrm{~K}$ [18]. Thermodynamic analysis suggests that at 1bar, $2500 \mathrm{~K}$ only $2.69 \%$ of water is actually dissociated to yield hydrogen [19] which increases to $25 \%$ at 0.05 bar, $2500 \mathrm{~K}$ [20]. Thus, from a thermodynamic perspective, high temperature and low pressure conditions are preferred for higher hydrogen yield.

As solar thermolysis occurs at very high temperature, special material like zirconia [21] and zeolites [22] were proposed to be used at this condition. However, zirconia membrane [23] and ceramic based porous zirconia membrane [24] material undergo rapid sintering at $2100 \mathrm{~K}$ and are not suitable for operation at these elevated temperature conditions. Thus, no material could be developed that can sustain the elevated temperature required for solar thermolysis. As a result of this experience, efforts were directed to lower the temperature of solar thermolysis by using catalysts. However, experimental investigations reveal 
that water dissociation on solid acid material like $\mathrm{Al}_{2} \mathrm{O}_{3}, \mathrm{SiO}_{2}$, $\mathrm{CaCO}_{3}, \mathrm{TiO}_{2}$ gives a peak hydrogen yield of only $0.30 \%$ (with $\mathrm{Al}_{2} \mathrm{O}_{3}$ ) at $1073 \mathrm{~K}$ [25].

Another problem with solar thermolysis is associated with the separation of explosive hydrogen-oxygen mixture. There are two ways of separating thermolysis products, either by direct separation at very high temperature or by rapid quenching followed by low temperature separation [26]. High temperature separation is achieved by separating hydrogen in micro porous or metallic/non-metallic membrane, oxygen in electro-diffusion, high speed jet and centrifugation. Low temperature separation is achieved with quench process by using auxiliary jets and introducing hot gases in water [26]. However, these methods for separation of hydrogen-oxygen mixture have not been successfully demonstrated and issues with separation still exist.

It can be observed that requirement of high temperature is an impeding force in development of solar thermolysis and with the current state of technology this is not a viable option. High temperature electrolysis, where the temperature required for dissociation of water is brought down by supplying a part of energy in the form of electricity, might be a viable alternative. The cost of hydrogen obtained by high temperature electrolysis, with a parabolic trough solar field for steam generation and PV plant for electrolysis, is estimated at 5.23\$/kg [27]. On experimental front, steam electrolysis at $1103 \mathrm{~K}$ was demonstrated for over $400 \mathrm{~h}$ and average hydrogen production rate of $0.9 \mathrm{Nm}^{3} / \mathrm{h}$ was achieved [28]. However, high temperature electrolysis using solar heat and electricity has not yet been demonstrated.

\section{Municipal Waste Treatment}

Solar drying of municipal waste is employed to achieve a reduction of the mass and volume of moist organic rich waste material before its further disposal. It also serves to increase the calorific value of such material in preparation to a possible thermal or biological utilisation.

Solar radiation as a freely available energy source is predominantly used for the drying process. The drying is taking place in a modular solar dryer with forced convection, of which the design supports the heating and air circulation.

The driving force of drying is the difference between the partial vapour pressure inside the waste and the ambient air. The warmer the air the more water vapour can be transported. To intensify the drying and minimize the total drying time, the air flow is set at $0.083 \mathrm{~m}^{3} \mathrm{~s}^{-1}$.

Dried municipal waste, have qualities and characteristics that make them suitable for application on earth. Most of the materials produced by dry heat in Morocco applied to land as a soil conditioner, fertilizer or fertilizer supplement. The material is used by agricultural users (farmers), golf courses, nurseries, parks [29].

\section{E. Wastewater Treatment}

Wastewater must not simply be abandoned, and a solution such as wastewater treatment plant should be developed to produce drinkable water from wastewater as well as other water with lower quality for gardening, cleaning uses, cooling, and other industrial demands. In all cases of wastewater treatment, the drying process is considered a basic stage after the mechanical dewatering, which maybe done by filtration or centrifugation [30]. Dewatering up to $35 \%$ of solids and sanitary landfilling have been indicated as the most common form of sludge disposal [31], [32]. Water that contains sewage sludge can simply be removed to a certain extent, and further moisture can be expelled by drying and thermal process. After this process, the dry solid content in the water can be reduced to less than $5 \%$, this type of sewage sludge has lower mass and volume and, consequently, the cost of storage, handling, transportation, and landfilling will be reduced [30].

The other type of wastewater that requires treatment is olive mill wastewater(OMW). The OMW drying process, which uses an indirect type of natural convection solar dryer, is presented for energy-exergy analysis [33]. OMW is produced when vegetable water and fresh water are used in the extraction of olive oil from the plant. OMW contains olive pulp, mucilage, pectin, residual oil, and different dissolved mineral salts [34]. The production of more olive oil in the industry, especially in the southern regions of Europe, such as Spain, causes environmental problems because of the large amount of sludge and OMW. For example, the total amount of olive processed in Spain reaches an approximately $5.5 \times 10^{6} \mathrm{t}$, which generates $4 \times 10^{6} \mathrm{t} /$ year of wastewater [30]. Thus, the drying system plays a significant role in such areas to reduce the volume, weight, and size of OMW and in mitigating the environmental effects and cost of storage, handling, transportation, and sanitary landfilling [30]. Many drying systems function directly with fossil fuels or with the aid of combined heat and power(CHP) processes. CHP processes are utilized to enhance the efficiency of plants; however, applying solar drying may have long pay back periods. Therefore, substituting the solar dryer in this case is difficult [35].

\section{F. Food Waste Treatment}

The waste matter may comprise of biodegradable waste matter or organic waste matter, such as food waste. The fuel cell system uses the produced biogas as a fuel for converting chemical energy in the fuel to electrical energy or electricity through a chemical reaction. Other aspects, functions, and features of the fuel cell system would be apparent and readily understood by a person having ordinary skill in the art. The system further comprises one or a plurality of or a set of solar panels disposed at the top of the waste management facility. The solar panels may be installed on the rooftop of the waste management facility for maximum exposure to the sun. The position of the solar panels may be varied accordingly in order to receive the maximum amount of sunlight or solar irradiance. The solar panels are configured for harnessing solar energy from sunlight, and converting the solar energy into electrical energy or electricity. The solar panels an comprise of building-integrated photovoltaics (BIPV), which are materials that utilize thick inorganic cells of crystalline silicon in poly-crystalline wafers. Under direct sunlight, the solar panels on the waste management facility 100 are estimated to be able deliver approximately 10 to 12 watts of power per square foot [36].

The solar panels are conductively connected or coupled to 
the battery. The solar energy collected by the solar panels is converted into electrical energy or electricity, which will go through a charge controller for regulating the power conducted into the battery. Alternatively, the electrical energy or electricity may be directed to an independent battery system. When the battery is fully charged, stored energy or electricity in the battery will be conducted or transmitted out for utilization by the waste management facility. Alternatively, stored energy or electricity in the battery can be conducted or transmitted out while the battery is continually being charged by the electrical energy generated by the solar panels.

Therefore, a part or at least a portion of the electricity generated by the combustion system and the solar panels can be fed to the common power grid supplying domestic power/electricity requirements of the residential area. The other parts or portions of the electricity generated are supplied to the waste management facility for helping to meet the energy requirements of managing waste matter and processing waste matter to generate energy, as described above. Alternatively, the entire electricity generated can be re-utilized for meeting the energy requirements of processing waste matter to generate energy, such us with the anaerobic digester, without any contribution to the common power grid supplying domestic power/electricity requirements of the residential area. Thus, an advantage of the waste matter management system is that the waste management facility forms an integrated system of energy generating and converting technologies. The electricity generated by the anaerobic digester and the solar panels can be used to power, at least partially, other components and machines in the waste management facility, making the waste management facility and the overall system self-sustainable.

As described in the embodiments above, the waste matter management system and method generates energy or electricity by processing waste matter. There is thus an advantage of utilizing or recycling waste matter more efficiently for producing energy, thereby helping the society and the country save up on other valuable and expensive sources of energy such as hydrocarbons. The space and volume occupied by the waste management facilities, also known as bin centres, in the residential localities can be utilized for power generation more efficiently. The processing or digestion of organic waste matter in the bin centres will reduce the stench and smells substantially, thereby improving the quality of lives of people and residents in the neighbourhood. The organized removal and disposal of organic waste matter for power generation can improve the overall hygiene and neatness of the neighbourhood. This can directly and indirectly lead to reduced chances of diseases and infections in the neighbourhood. Another advantage can be a reduction in the number of birds in the locality looking for food in the collected waste matter and subsequent reduction in their predators as well, leading to improved hygiene and liveable conditions in the residential areas.

\section{CONCLUSION}

This work summarized the research and development work for solar drying. It is hoped that this review work maybe valuable and appropriate for greenhouse gas reduction technology.

Solar drying is another very important application of solar energy. Solar energy is feasible for the drying system, including industrial processes, given the amount of energy consumed by dryers and considering that solar radiation is unlimited and available in most parts.

Therefore, try to study in order to find the optimal energy requirements and conditions to reduce greenhouse gases. As a result, the method by using solar drying, which is highly effective and relatively easy could be appropriate choice. Further study would be continued comparing advantages and disadvantages in this laboratory.

\section{ACKNOWLEDGMENT}

This work is financially supported by Korea Ministry of Environment(MOE) as $\ulcorner$ Knowledge-based environmental service Human resource development Project $\lrcorner$.

\section{REFERENCES}

[1] C. L. Hii, S. V. Jangam, S. P. Ong, and A. S. Mujumdar, "Solar drying Fundamentals," Applications and Innovations, 2012.

[2] A. Delyannis, "Solar stills provide island inhabitants with water," Sun at Work, vol. 10, no. 1, pp. 6-8, 1967

[3] A. B. Meinel and M. P. Meinal, "Appl. solar energ," An Introductuction, Addison-Wesley Publishing Company, Reading, MA, 1976.

[4] S. A. Kalogirou, "Solar energy Engineering processes and systems," 2009.

[5] R. C. Jordan and W. E. Ibele, "Mechanical energy from solar energy," in Proc. the World Symposium on Applied Solar Energy, pp. 81-101, 1956

[6] SERI, "Power from the Sun: Principles of high temperature solar thermal technology," 1987.

[7] O. V. Ekechukwu, "Review of solar-energy drying systems I: an overview of drying principles and theory," Energy Conversion and Management, vol. 40, pp. 593-613, 1999.

[8] A. S. Mujumdar, "Handbook of Industrial drying," Taylor and Francis Group, U.K., 2007.

[9] J. H. Perry, Chemical Engineering Handbook, 8th ed., McGraw-Hill, New York, p. 28, 2007.

[10] D. Jain and G. N. Tiwari, "Thermal aspects of open sun drying of various crops," Energy, vol. 28, pp. 37-54, 2003.

[11] S. Mekhilefa, R. Saidurb, and A. Safari, "A review on solar energy use in industries," Renewable and Sustainable Energy Reviews, vol. 15, pp. 1777-1790, 2011

[12] Z. Xingxing et al., "Review of R\&D progress and practical application of the solar photovoltaic/thermal (PV/T) technologies," Renewable and Sustainable Energy Reviews, vol. 16, pp. 599-617, 2012.

[13] N. K. Bansal and G. Minke "Climatic zones and rural housing in India," Kernforschungsanlage, Juelich, Germany, 1988.

[14] H. Kaptan and A. Seylam, "Solar drying of selected fruits and vegetables," TUBITAK-MRC, FSTRI, 1996.

[15] M. Urbaniak and B. Hillebrand, "Sludge drying and granulation for their further use," Mat. XVI Konferencji Naukowo-Technicznej nt. Aktualne problemy gospodarki wodno-ściekowej, 2004.

[16] Bank aus Verantwortung KFW, "Solar sludge drying in the WWTP of Managua - Nicaragua,” 2013.

[17] D. Yadav and R. Banerjee, "A review of solar thermochemical processes," Renewable and Sustainable Energy Reviews, vol. 54, pp. 497-532, 2016.

[18] C. Perkins and A. Wiemer "Likely near-term solar-thermal water splitting technologies," Int J Hydrog Energy, vol. 29, pp.1587-99, 2004.

[19] S. Baykara, "Hydrogen production by direct solar thermal decomposition of water, possibilities for improvement of process efficiency," Int J Hydrog Energy, vol. 29, pp. 1451-1458, 2004.

[20] A. Kogan, E. Spiegler, and M. Wolfshtein "Direct solar thermal splitting of water and on-site separation of the products. III. Improvement of reactor efficiency by steam entrainment," Int J Hydrog Energy, vol. 25, pp.739-745, 2000. 
[21] J. Fan et al., "High flux zirconia composite membrane for hydrogen separation at elevated temperature," J Membr Sci, vol. 170, pp.113-25, 2000.

[22] M. Momirlan and R. Birjega, "Structure of zeloties used in hydrogen evolution from water," Int J Hydrog Energy, vol. 22, pp. 133-136, 1997.

[23] A. Kogan, "Direct solar thermal on-site separation of the products-II. Experimental feasibility study," Int J Hydrog Energy, vol. 23, pp. 89-98, 1998

[24] A. Kogan, "Direct solar thermal splitting of water and on-site separation of the products - IV. Development of porous ceramic membranes for a solar thermal water-splitting reactor," Int J Hydrog Energy, 25, pp. 1043-50, 2000.

[25] Y. S Cho and J. H. Kim, "Hydrogen production by splitting water on solid acid materials by thermal dissociation," Int J Hydrog Energy vol 36, pp. 8192-202, 2011.

[26] S. Baykara, "Experimental solar water thermolysis," Int J Hydrog Energy, vol. 29, pp.1459-69, 2004.

[27] S. K. Ngoh, L. M. A. Ohandja, A. Kemajou and L. Monkam, "Design and simulation of hybrid solar high-temperature hydrogen production system using both solar photovoltaic and thermal energy," Sustain Energy Technol Assess, vol. 7, pp. 279-93, 2014.

[28] M. G. Mckellar et al., "Demonstration and system analysis of high temperature steam electrolysis for large-scale hydrogen production using SOFCs," Idaho, 2008.

[29] A. Idlimam et al., "Solar convective drying in thin layers and modeling of municipal waste at three temperatures," Applied Thermal Engineering, vol. 108, pp. 41-47, 2016.

[30] L. Bennamoun, "Solar drying of wastewater sludge:a review," Renew Sustain Energy Rev, vol. 16, no. 1, pp. 1061-1073, 2012.

[31] N. K. Salihoglu et al., "Solar drying in sludge management in Turkey," Renew Energy, vol. 32, no. 10, pp. 1661-1075, 2007.

[32] Official Gazette, "Turkish solid waste control regulations. M.O.E.," Ministry of Environment, Turkey, 1991

[33] A. R. Celma and F. Cuadros, "Energy and exergy analyses of OMW solar drying process," Renew Energy, vol. 34, no. 3, pp. 660-666, 2009.

[34] G. Greco, G. Toscanoa et al., "Dephenolisation of olive mill waste-waters by olive husk," Water Res, vol. 33, no. 13, pp.3046-3050, 1999.

[35] J. P. Spets and P. Ahtila, "Improving the power-to-heat ratioin CHP plants by means of a biofuel multistage drying system," Appl Therm Eng, vol. 22, no. 10, pp. 1175-1180, 2002.
[36] Y. J. Ban, "Waste matter management system and method Patent," WO2015183204A1, December 12, 2015.

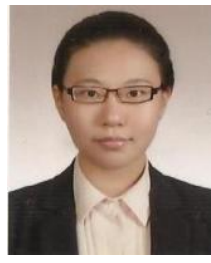

Ji Ye Yoo graduated from Incheon National University, and got the master degrees in same university. Her major fields of research are the air pollution control, greenhouse gas and odor management. She is now enrolled in a doctoral course at the Department of Climate International Cooperation, Incheon National University, Republic of Korea.

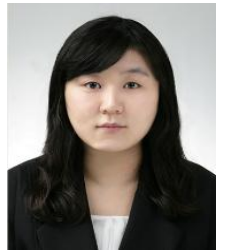

Hee Jung Kim graduated from the Department of Environmental Engineering, University of Incheon. She attends in master's course of Dept. of Environment and Energy Engineering in Graduate School of Incheon National University.

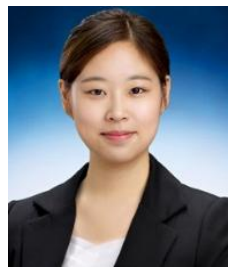

Eun Ji Woo was born in Republic of Korea on $14^{\text {th }}$ March 1992. She attends in master's course of Dept. of Environment and Energy Engineering in Graduate School of Incheon National University.

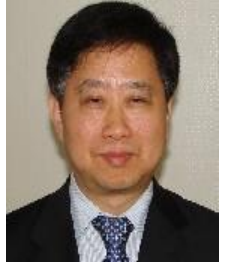

Chan Jin Park graduated from Korea University, and got the master and $\mathrm{PhD}$ degrees in same university. His major fields of research are the air pollution control, greenhouse gas technology and odor management technology. His interests are green growth policy. He is now full-professor in Incheon National University at Urban and Environmental Engineering School. 